\title{
Correction to: Development of Decisional Values Statements for Lung Cancer Screening among African American Smokers
}

\author{
Randi M. Williams ${ }^{1}$ (D) $\cdot$ Kenneth H. Beck ${ }^{2}$. James Butler $\mathrm{III}^{2} \cdot$ Sunmin Lee ${ }^{2} \cdot$ Min Qi Wang $^{2} \cdot$ Kathryn L. Taylor ${ }^{1}$. \\ Cheryl L. Knott ${ }^{2}$
}

Published online: 27 January 2020

(C) American Association for Cancer Education 2020

\section{Correction to: Journal of Cancer Education}

https://doi.org/10.1007/s13187-020-01687-4

The original version of this article unfortunately contained mistakes in Tables 1 and 3. The corrected Tables are as follows.

The original article has been corrected.

The online version of the original article can be found at https://doi.org/ 10.1007/s13187-020-01687-4

Randi M. Williams

rmw27@georgetown.edu

1 Department of Oncology, Cancer Prevention and Control Program, Lombardi Comprehensive Cancer Center, Georgetown University Medical Center, 3300 Whitehaven Street NW Suite 4100,

Washington, DC 20007, USA

2 Department of Behavioral and Community Health, School of Public Health, University of Maryland, College Park, MD, USA 
Table 1 Categories generated from key informant interviews $(n=9)$

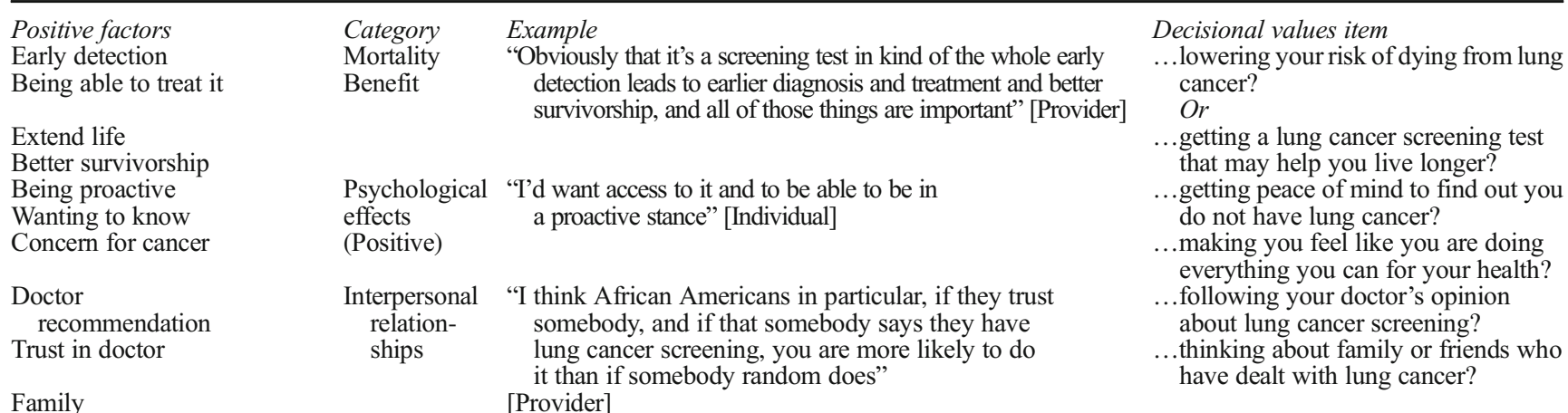
history/personal
experience with
cancer

Non-invasiveness of test

[Provider]

"So I think if I knew if you get early, and I think I do

know that just by reading and different people in my life that I've known, you can be cured....especially if I had a history of lung cancer in my family" [Individual]

Test itself

"I think positive things are knowing that it's a noninvasive test, is really important" [Provider]

...knowing the test has little risk?

\section{Negative factors \\ Covered by insurance}

Cost

\author{
Access \\ Additional \\ follow-up tests \\ Overwhelmed by \\ tests \\ Age/life expectancy \\ Other medical issues \\ that need to be
} addressed

Do not want to know results Cannot change it

Fear of death due to cancer

Fear of finding something

Fear cancer will spread

Fear of undergoing procedures

Scared of results

Concerns about findings

Finding some other major medical problem

Not picking something up that may be there

Limitations of screening
Category Example

Burden of test "Well number one, I'm not sure if this test is covered by my itself insurance, health insurance." [Individual]

Hierarchy of "Unfortunately once you reach a certain age, okay, you start life thinking about life. And I say life instead of death" priorities [Individual]

"... do not know that screening becomes the number one priority when someone else has other medical issues to address" [Provider]

Fear/fatalism "They do not really want to know" [Provider]

"The negative things. I do not want to know, and then I think I'm at this stage, losing my mother and everything. I do not think I could handle one more thing" [Individual]
Decisional values item

...the out of pocket cost of the screening?

... where you have to go (testing location) to get lung cancer screening?

...the idea that lung cancer screening may lead to more testing if there is an abnormal result?

...the idea that you would prefer to focus on other things in your life than thinking about screening for lung cancer?

...the idea that lung cancer screening will make you worry about lung cancer?
Limitations Note: This was based upon the limitations screening of the test
Stigma of lung cancer Guilt of smoking
Stigma

\footnotetext{
"There is a lot of baggage that comes with lung cancer screening.
For smokers, that is the guilt and the shame and the nihilism on their part and on the healthcare system's part." [Provider]
}

...the idea that lung cancer screening will not find all lung cancers or all lung cancers early?

...the idea that not all patients who have lung cancer diagnosed by screening will avoid death from lung cancer?

...the idea that the lung cancer screening test might show something wrong that turns out not to be cancer? ...the idea that getting screened for lung cancer would make you feel badly about your smoking history? 
Table 1 (continued)

\begin{tabular}{|c|c|c|c|}
\hline \multicolumn{3}{|l|}{ Ashamed } & $\begin{array}{l}\text {...the feeling that if you had lung cancer } \\
\text { you would feel like it was your fault? }\end{array}$ \\
\hline Invasiveness & Test itself & $\begin{array}{l}\text { "It's still very difficult to convince people that the benefit is } \\
\text { worth it relative to the other cancers because I think also } \\
\text { the invasiveness of proving it ismore risky than say, } \\
\text { mammograms and finding something abnormal on a } \\
\text { mammogram" [Provider] }\end{array}$ & ...knowing the test has little risk? \\
\hline
\end{tabular}

Table 3 Pattern coefficients for the retained factors for the decisional values measure

\begin{tabular}{|c|c|c|c|}
\hline Item & $\mathrm{M}(\mathrm{SD})$ & $\begin{array}{l}\text { Cons of screening factor } \\
\text { loading }\end{array}$ & $\begin{array}{l}\text { Pros of screening factor } \\
\text { loading }\end{array}$ \\
\hline \multicolumn{4}{|c|}{$\begin{array}{l}\text { Below are listed some things that people consider when making a decision about lung cancer screening using low-dose computed tomography. Please } \\
\text { indicate how important these are to you by selecting "extremely important to me" to "not at all important to me." How important is... }\end{array}$} \\
\hline ...lung cancer screening may lead to more testing if there is an abnormal result? & $4.2(1.2)$ & 0.923 & \\
\hline $\begin{array}{l}\text {...not all patients who have lung cancer diagnosed by screening will avoid death } \\
\text { from lung cancer? }\end{array}$ & $4.1(1.1)$ & 0.810 & \\
\hline ...lung cancer screening will not find all lung cancers or all lung cancers early? & $4.1(1.2)$ & 0.786 & \\
\hline $\begin{array}{l}\text {...the lung cancer screening test might show something wrong that turns out not } \\
\text { to be cancer? }\end{array}$ & $4.1(1.1)$ & 0.753 & \\
\hline ...the out of pocket cost of the screening? & $4.0(1.3)$ & 0.652 & \\
\hline $\begin{array}{l}\text {... getting screened for lung cancer would make you feel badly about your } \\
\text { smoking history? }\end{array}$ & $4.0(1.1)$ & 0.621 & \\
\hline ...if you had lung cancer you would feel like it was your fault? & $3.9(1.2)$ & 0.496 & \\
\hline ...making you feel like you are doing everything you can for your health? & $4.5(0.82)$ & & -0.918 \\
\hline ...following your doctor's opinion about lung cancer screening? & $4.4(0.90)$ & & -0.911 \\
\hline ...knowing the test has little risk? & $4.4(1.0)$ & & -0.829 \\
\hline ...lowering your risk of dying from cancer? & $4.5(0.84)$ & & -0.719 \\
\hline ...thinking about family or friends who have dealt with lung cancer & $4.3(1.0)$ & & -0.676 \\
\hline
\end{tabular}

Publisher's Note Springer Nature remains neutral with regard to jurisdictional claims in published maps and institutional affiliations. 